\title{
Assessment of sperm quality and short term preservation of sperm in grey mullet Mugil cephalus Linnaeus, 1758
}

\author{
BALAMURUGAN RAMACHANDRAN AND MUNUSWAMY NATESAN \\ Unit of Aquaculture and Cryobiology, Department of Zoology, University of Madras, Guindy Campus \\ Chennai - 600 025, Tamilnadu, India \\ e-mail:munuswamynm@yahoo.com
}

\begin{abstract}
Quality of fresh milt of grey mullet Mugil cephalus Linnaeus, 1758 was assessed based on motility grade, motility duration, sperm count and seminal plasma osmolality. Freshly collected milt from live males $(n=17)$ were examined individually for motility assessment. Motility grade was four in fifteen samples whereas three in other two samples analysed. Other sperm quality parameters such as motility duration, sperm density and seminal plasma osmolality were : $421.38 \pm 137 \mathrm{sec}$, $1.67 \pm 0.3 \times 10^{8}$ nos. $\mathrm{ml}^{-1}$ and $362.28 \pm 79.13 \mathrm{~m} \mathrm{Osmol} \mathrm{kg}^{-1}$ respectively. To standardise short term preservation of sperm, four different extenders such as ringer solution for marine fish, modified marine fish ringer solution, V2E extender and honey in fish ringer solution were experimented. The results indicated that short term preservation at $4^{\circ} \mathrm{C}$ over a period of 10 days with V2E extender at 1:1 ratio significantly $(\mathrm{p}<0.05)$ retained the highest sperm motility grade $(2.6 \pm 0.5)$ over other dilutions such as $1: 2$ and $1: 3$ on $5^{\text {th }}$ day. However, on $10^{\text {th }}$ day of observation, sperms were immotile after activation with seawater, in undiluted as well as diluted milt samples. This probably indicates that V2E extender is effective for short term preservation of sperm in grey mullet.
\end{abstract}

Keywords: Extender, Milt, Motility, Mullet, Osmolality

Grey mullet Mugil cephalus Linnaeus, 1758 is widely cultured in fresh and brackishwater fish ponds throughout the world. Due to its benthic feeding habit it is considered an efficient bioremediator in aquaculture systems (Lupatsch et al., 2003). In India, the farming activities of grey mullet are fully dependent on the fingerlings collected from wild and the hatchery seed production technology of this species under captive condition is at early stages. Generally, the grey mullet spawns in the sea and bar mouth of estuaries (Kurian, 1960) but, they can grow and thrive very well in lower salinity waters. However, under captive conditions, M. cephalus do not spawn spontaneously, with both male and female showing reproductive dysfunctions, even when maintained in full strength seawater (Joseph et al., 2005). In Hawaii, mullet males have been found to mature earlier than females under captivity and release milt (Weber and Lee, 1985). However, in most cases, the released milt is highly viscous and fails to fertilise the eggs during natural fertilisation (Shehadeh et al., 1973). In this context, there have been no detailed investigations on sperm quality in M. cephalus. Earlier studies on the male gametes of grey mullet are confined to sperm ultrastruture (Kumar et al., 2015). However, attempts have been made to cryopreserve the sperm of grey mullet (Chao et al., 1973). Studies related to short term preservation and cryopreservation of sperm in M. cephalus is scanty in India (Diwan and Nandhakumar,
1998). Species specific preservation protocols for male gametes are not developed for many fish species (Rana, 1995). The reported procedures of short term storage of fish sperm allow prolonging the viability for only 1 - 2 weeks post-collection (Stoss et al., 1983; Rana, 1995). Therefore, most suitable short term preservation protocol to maintain good quality sperm without affecting their motility and fertilisation ability may be of great importance to augment viability of the sperm (Scott and Baynes, 1980). Hence, the present study was undertaken to assess the sperm quality in freshly collected milt and to optimise suitable extender for short term preservation of sperm at $4^{\circ} \mathrm{C}$.

Live mature male mullets (body weight $383.4 \pm 135.0 \mathrm{~g}$, total length $=29.2 \pm 3.72 \mathrm{~cm}$ ) captured in the inshore waters of Kovalam, south of the Bay of Bengal during the natural spawning season (September - December) of 2014-15 were procured from local fishermen. Oozing condition of male was ascertained by slight abdominal pressure. For milt collection, urogenital area was cleaned with a wet towel before the milt was hand-stripped into clean dry $2.0 \mathrm{ml}$ centrifuge tubes. Collected milt samples were immediately kept in a box containing crushed ice and shipped to the laboratory and stored at $4^{\circ} \mathrm{C}$ until further analysis. For motility assessment, sperm was activated by placing approximately $5 \mu \mathrm{l}$ fresh milt on to a microscope 
slide and diluted with $50 \mu \mathrm{l}$ of filtered natural seawater (osmolality - $971 \mathrm{~m} \mathrm{Osmol} \mathrm{kg}{ }^{-1}$, salinity - 33 \%o, $\mathrm{pH}$ - 8.1). The motility grade of freshly collected milt sample was assessed individually using light microscope (x400 magnification. Motility was assessed as described by Ding et al. (2011) with slight modifications. Motility grades were ascertained from 0 - 4 where, $0=$ No motility; $0.5<10 \%$ sperm moving, slow swimming; $1=10-30 \%$ sperm moving, slow swimming); $2=30-50 \%$ sperm moving, slow swimming; $3=50-80 \%$ sperm moving, fast swimming and $4=80-100 \%$ sperm moving, fast swimming. All samples were analysed at a time to avoid subjective differences in motility grades. Duration of sperm motility (seconds) was calculated by recording the duration of activation until all spermatozoa movements stopped. Sperm density was measured using an improved Neubauer (BOECO, Hamburg, Germany) counting chamber (Agarwal and Raguvanshi, 2009). Due to high viscosity of milt, pooled milt samples from different male individuals were used for seminal plasma separation. Seminal plasma was collected after centrifugation (KOBOTA-KR-1500, Japan) at $8854 \mathrm{~g}$ for $30 \mathrm{~min}$ at $4^{\circ} \mathrm{C}$. Supernatant was collected and again centrifuged at $553 \mathrm{~g}$ for $10 \mathrm{~min}$ at $4^{\circ} \mathrm{C}$ to obtain clear seminal plasma. The osmolality of seminal plasma was determined using an Osmometer 3000 (Gonotech, Berlin Germany). Four different extenders such as ringer solution for marine fish (RSMF, Chao et al., 1973), modified marine fish ringer solution (MMFR, Kurokura et al., 1984), V2E (Stein and Bayrle, 1976) and honey in fish ringer solution (HFRS, Hara et al., 1982) were selected. All the extenders were prepared fresh using double distilled water. The ionic composition, $\mathrm{pH}$ and osmolality of the extenders are given in Table 1. For short term preservation study, fresh milt samples showing motility grade '4' were only used for experiments. Since the milt volume from individual fish is not sufficient, milt collected from different individuals (motility grade '4') were pooled and used. Triplicate milt samples were diluted at ratios of $1: 1,1: 2$ and $1: 3$ with the selected extenders. The diluted milt samples were transferred to clean $2.0 \mathrm{ml}$ centrifuge tubes, labeled and stored at $4^{\circ} \mathrm{C}$. At 5 days intervals, less than $5 \mu \mathrm{l}$ of diluted milt was activated and assessed for motility. A minimum of three motility assessments were made for each sample. Undiluted milt sample was used as control. Data obtained from short term storage study were subjected to analysis of variance (ANOVA) and subsequently with Duncan's New Multiple Range Test $(p<0.05)$. Statistical analysis was performed using SPSS version 16.0 (SPSS Inc., Chicago, IL, USA).

Milt of $M$. cephalus is highly viscous, white in colour and the quantities of milt varied among individuals and ranged from 0.1 to $2.0 \mathrm{ml}$ with maximum motility $(80-100 \%)$ in freshly collected milt. Freshly collected milt free from urine, faecal, blood and seawater contamination were only used for anlyses. Of the freshly collected milt samples $(\mathrm{n}=17)$ subjected to motility assessment, motility grade recorded was $4(80-100 \%$ sperm moving, fast swimming) in fifteen fishes and 3 (50-80\% sperm moving, fast swimming) in two fishes. Contaminated milt samples turned light yellow after certain hours of storage and at that stage motility of sperm completely ceased. At $4^{\circ} \mathrm{C}$, the fresh milt could be maintained in centrifuge tubes up to $48 \mathrm{~h}$ without much difference in motility. General sperm characteristics of the fresh milt of $M$. cephalus are shown in Table 2.

Of all the extenders used, milt diluted with V2E at 1:1 dilution showed significantly higher motility grade $(2.67 \pm 0.58)$ on the fifth day followed by RSMF $(2.33 \pm 0.58)$ and MMFR (2.33 \pm 0.58$)$ (Table 3$)$. Motility grade of sperm in undiluted and diluted milt was same initially (observations were made immediately after

Table 2. General sperm quality in fresh milt

\begin{tabular}{llll}
\hline Sperm quality parameters & $\mathrm{n}$ & Range & Mean \pm SD \\
\hline Motility duration (seconds) & 14 & $287-710$ & $421.38 \pm 137$ \\
Sperm density $\left(10^{8} \mathrm{ml}^{-1}\right)$ & 17 & $1.2-2.4$ & $1.675 \pm 0.337$ \\
Osmolality $\left(\mathrm{mOsmol} \mathrm{kg} \mathrm{kg}^{-1}\right)$ & 8 & $242-438$ & $362.28 \pm 79.13$ \\
\hline
\end{tabular}

Table 1. Composition and osmolality of the extenders

\begin{tabular}{lllll}
\hline Ions $(\mathrm{mM})$ & Ringer solution for marine fish (RSMF) & Modified marine fish ringer solution (MMFR) & V2E (V2E) & Honey in fish ringer solution (HFRS) \\
\hline $\mathrm{NaCl}$ & 231 & 111.22 & 128.5 & 128.5 \\
$\mathrm{KCl}$ & 8 & 40 & 5.10 & 8 \\
$\mathrm{NaHCO}_{3}$ & 2.38 & 2 & 24 & 24 \\
$\mathrm{CaCl}_{2}$ & 2.23 & 2.7 & - & 5.4 \\
$\mathrm{MgCl}_{2}$ & 3.67 & - & - & 3.67 \\
$\mathrm{Glucose}$ & - & - & 1 & - \\
Egg yolk (ml) & - & - & 0.1 & - \\
$\mathrm{Honey}(\mathrm{ml})$ & - & - & - & 1 \\
$\mathrm{pH}$ & 7.4 & 7.9 & 8.2 & 7.5 \\
Osmolality $\left(\mathrm{mOsmol} \mathrm{kg}{ }^{-1}\right)$ & $466 \pm 22.3$ & $300 \pm 12.6$ & $306 \pm 5.50$ & $286 \pm 6.02$ \\
\hline
\end{tabular}

Extenders composition are based on RSMF = Chao et al. $(1973)$, MMFR = Kurokura et al. $(1984)$, V2E = Stein and Bayrle (1976), HFRS = Hara et al. $(1982)$ 
Table 3. Changes in motility grade of sperm during short term storage for 10 days

\begin{tabular}{|c|c|c|c|c|}
\hline \multirow{2}{*}{ Dilution ratio } & \multirow{2}{*}{ Treatments } & \multicolumn{3}{|c|}{ Storage days } \\
\hline & & 0 & 5 & 10 \\
\hline \multirow[t]{5}{*}{$1: 1$} & Undiluted milt (Control) & $3.33 \pm 0.58^{\mathrm{a}}$ & $1.33 \pm 0.58^{\mathrm{b}}$ & $0^{\mathrm{c}}$ \\
\hline & RSMF & $3.33 \pm 0.58^{\mathrm{a}}$ & $2.33 \pm 0.58^{\mathrm{b}}$ & $0^{c}$ \\
\hline & MMFR & $3.33 \pm 0.58^{\mathrm{a}}$ & $2.33 \pm 0.58^{\mathrm{b}}$ & $0^{\mathrm{c}}$ \\
\hline & V2E & $3.67 \pm 0.58^{\mathrm{a}}$ & $2.67 \pm 0.58^{\mathrm{b}}$ & $0^{c}$ \\
\hline & HFRS & $2.67 \pm 0.58^{\mathrm{a}}$ & $0^{\mathrm{b}}$ & $0^{\mathrm{b}}$ \\
\hline \multirow[t]{4}{*}{$1: 2$} & Undiluted milt (Control) & $3.66 \pm 0.58^{\mathrm{a}}$ & $1.33 \pm 0.58^{\mathrm{b}}$ & $0^{\mathrm{c}}$ \\
\hline & RSMF & $3.33 \pm 0.58^{\mathrm{a}}$ & $0.83 \pm 0.29^{\mathrm{b}}$ & $0^{\mathrm{c}}$ \\
\hline & MMFR & $3.66 \pm 0.58^{\mathrm{a}}$ & $0.66 \pm 0.29^{b}$ & $0^{c}$ \\
\hline & V2E & $3.66 \pm 0.58^{\mathrm{a}}$ & $1.33 \pm 0.58^{b}$ & $0^{\mathrm{c}}$ \\
\hline \multirow[t]{4}{*}{$1: 3$} & Undiluted milt (Control) & $3.66 \pm 0.58^{\mathrm{a}}$ & $1.33 \pm 0.58^{\mathrm{b}}$ & $0^{c}$ \\
\hline & RSMF & $3.33 \pm 0.58^{\mathrm{a}}$ & $0.83 \pm 0.29^{b}$ & $0^{c}$ \\
\hline & MMFR & $3.66 \pm 0.58^{\mathrm{a}}$ & $0.5 \pm 0.00^{\mathrm{b}}$ & $0^{c}$ \\
\hline & V2E & $3.66 \pm 0.58^{\mathrm{a}}$ & $0.83 \pm 0.29^{b}$ & $0^{\mathrm{c}}$ \\
\hline
\end{tabular}

Values bearing different superscripts in the same row are significantly different $(\mathrm{p}<0.05)$

dilution) but gradually declined with advancement of storage days $(\mathrm{p}<0.05)$. With 1:2 dilution, motility grades were $1.33 \pm 0.58,0.83 \pm 0.29$ and $0.66 \pm 0.29$ respectively for the extenders V2E, RSMF and MMFR on the $5^{\text {th }}$ day. At $1: 3$ dilution, motility grade reduced to $0.83 \pm 0.29$ in RSMF, $0.83 \pm 0.29$ in V2E and $0.5 \pm 0.0$ in MMFR. In contrast, the motility grade in undiluted milt significantly $(\mathrm{p}<0.05)$ decreased to $1.3 \pm 0.57$ on fifth day. On the other hand, motility of sperm completely ceased on fifth day of observation in milt diluted at 1:1 ratio with HFRS. Therefore, in subsequent dilutions, such as 1:2 and 1.3, HFRS was not used. However, on tenth day of observation, in undiluted milt as well as in diluted milt samples with extenders, sperms were found immotile after activation with seawater.

Observations indicated that motility duration of the spermatozoa in $M$. cephalus, was up to $710 \mathrm{sec}$ after activation. These results are comparable with the observations reported in other marine fishes like Gadus morhua and Scothalmus maximus wherein spermatozoa showed active movement for $800 \mathrm{sec}$ (Cosson et al., 2008) and $600 \mathrm{sec}$ (Dreanno et al., 1999). Zaki et al. (1993) documented that motility duration of spermatozoa of grey mullet completely ceased at $420 \mathrm{sec}$ after activation with seawater. However, Yeganesh et al. (2008) observed motility duration up to $180 \mathrm{sec}$ in the same species.

In the present study, sperm count in fresh milt was found to be lower as compared to the earlier report by Chao et al. (1973). The variation observed in sperm quality in fresh milt may be due to various factors like age of the fish and rearing environment (Nagahama, 1994; Alavi and Cosson, 2005). In general, the osmolality of extender was used as the controlling point to develop extender for milt of many species to maintain the quiescent stage of sperm during preservation (Ohta and Izawa, 1996). The seminal plasma osmolality of $M$. cephalus ranged between 242 to $438\left(\mathrm{mOsmol} \mathrm{kg}^{-1}\right)$. Fish seminal plasma osmolality also vary between individuals of same species and this can be correlated with the 'thinning' (hydration) of the milt (Moraisawa et al., 1979). Earlier studies showed that M. cephalus milt was preserved for up to 23 days at $5^{\circ} \mathrm{C}$ with appreciable motility of sperm (Chao et al., 1973). Whereas, in the present study at the end of 10 days of preservation at $4^{\circ} \mathrm{C}$ the motility was completely ceased in control milt as well as in milt diluted with extenders. This suggests the need for selective storage of milt from different individual males without pooling them for short term preservation. It has been reported that, in some species, sperm quality may improve during short term preservation in well oxygenated condition (Donaldson et al., 2011; Ciereszko et al., 2000). Enriched oxygenated condition could be tested as a possible additional method for further improvement of the results obtained in this study. RSMF, MMFR and V2E extenders proved their suitability for preservation of $M$. cephalus milt. However, V2E extender yielded better result compared to RSMF and MMFR. This may be due to the fact that V2E extender had proper concentration of ions and egg yolk. Earlier, the suitability of V2E extender for cryopreservation of sperm has been demonstrated in a number of fresh and marine water fishes including carp Labeo rohita, Cyprinus carpio and mullet Liza parsia (Kurokura et al., 1984; Gopalakrishnan et al., 2000; Sukumaran et al., 2003). Dilution of milt in an extender is an important step for improving the quality of sperm after collection in aquatic animals (Ciereszko et al., 2000; Bobe and Labbe, 2009). Further, dilution ratio determines the success of short term preservation of milt at low temperature and production of fingerlings during fertilisation. In the present study, 
1:1 dilution was found to be the best compared to other dilution ratios. Motility grade of spermatozoa decreased at higher dilution ratios probably indicating that all the intrinsic substances present in the seminal plasma, for example protein, glucose and ions loses their role at higher dilution (Jimenez et al., 2006; Mommens et al., 2008). Chao et al. (1973) also recorded that 1:1 dilution ratio was acceptable for the sperm of $M$. cephalus, Acanthopagrus schleglii and Tilapia zilli. On the other hand, Sukumaran et al. (2003) reported that the extender $\mathrm{V} 2 \mathrm{E}$ in combination with various cryoprotectants yielded better results during cryopreservation of sperm in Liza parsia compared to ringer solution. Thus, short term preservation studies revealed that $M$. cephalus milt can be preserved using the extender $\mathrm{V} 2 \mathrm{E}$ at dilution ratio of 1:1 at $4^{\circ} \mathrm{C}$ for 1 week. However, further studies are required to improve the sperm motility for longer storage period at low temperature by modifying the extender composition. The data generated from sperm quality studies from the fresh milt will be useful for effective management of cryopreservation of gametes for captive seed production in hatcheries.

\section{Acknowledgements}

Financial assistance from the Department of Science and Technology (DST) Government of India, New Delhi (SR/SO/AS-59/2012) is gratefully acknowledged.

\section{References}

Agarwal, N. K. and Raghuvanshi, S. K. 2009. Spermatocrit and sperm density in snow trout Schizothorax richardsonii - correlation and variation during the breeding season. Aquaculture, 291: 61-64.

Alavi, S. M. H. and Cosson, J. 2005. Sperm motility in fishes (I) - Effects of $\mathrm{pH}$ and temperature. Cell. Bio. Inter., 29: 101-110.

Bobe, J. and Labbe, C. 2009. Chilled storage of sperm and eggs. In: Cabrita, E. and Herraez, P. (Eds.), Methods in reproductive aquaculture of marine and freshwater species. Press Boca Raton, p. 219-231.

Chao, N. H., Chen, H. P. and Liao, I. C. 1973 Study on cryogenic preservation of grey mullet sperm. Aquaculture, 5: 389-406.

Ciereszko, A., Glogowski, J. and Dabrowski, K. 2000. Biochemical Characteristics of seminal plasma and spermatozoa of freshwater fishes. In: Tiersch, T. R. and Green, C. C. (Eds.), Cryopreservation in aquatic species. World Aquaculture Society, Baton Rouge, Louisiana, p. 20-48.

Cosson, J., Groison, A. L., Suquet, M., Fauvel, C., Dreanno, C. and Billard, R. 2008. Studying sperm motility in marine fish: an overview on the state of the art. J. Appl. Ichthyol., 24: 460-486.

Ding, F., Ge, J., Hao, C., Zhang, M., Rommens, W. and Milley, J. E. 2011. Cryopreservation of sperm from
Atlantic halibut (Hippoglosus hippoglossus L.) for commercial application. Cryobiology, 63: 56-60.

Diwan, A. D. and Nandakumar, A. 1998. Studies on cryogenic preservation of sperm of certain cultivable marine fishes. Indian J. Fish., 45: 387-397.

Donaldson, E., Solar, I. I. and Harvey, B. 2011. Induced ovulation and spermiation and factors influencing gamete quality of fishes. In: Tiersch, T. R. and Green, C. C. (Eds.), Cryopreservation in aquatic species. World Aquaculture Society, Baton Rouge, Louisiana, p. 37-45.

Dreanno, C., Seguin, F., Cosson, J., Suquet, M. and Billard, R. 1999. Metabolism of turbot Scopthalmus maximus spermatozoa: relationship between motility, intracellular nucleotide content and mitochondrial respiration. Mol. Repro. Dev., 53: 113-125.

Gopalakrishnan, A., Ponniah, A. G. and Kuldeep, K. L. 2000. Fine structural changes of rohu (Labeo rohita) sperm after dilution with cryoprotectants. Indian J. Fish., 47: 21-27.

Joseph, A., Iris, M., Itai, T., Berta, L. S. and Hanna, R. 2005. Enhancing spawning in the grey mullet (Mugil cephalus) by removal of dopaminergic inhibition. Gen. Comp. Endocrinol., 142: 212-221.

Kumar, P., Saranya, V., Natarajan, M., Kailasam, M. and Biswas, G. 2015. Ultrastructure of grey mullet (Mugil cephalus, Linnaeus, 1758) spermatozoa as revealed from light, scanning and transmission electron microscopy. J. Appl. Ichthyol., 31: 1-7.

Kurian, C, V. 1960. Spawning of Mugil cephalus. Indian farming, 15: 10-11

Kurokura, H., Hirano, R., Tomita, M. and Iwahashi, M. 1984 Cryopreservation of carp sperm. Aquaculture, 37: 267-273.

Lupatsch, I., T. Katz, T. and Angel, D. L. V. 2003. Assessment of the removal efficiency of fish farm effluents by grey mullets a nutritional approach. Aquac. Res., 34: 1367-1377.

Mommens, M., Wojtczak, M., Ciereszko, A. and Babiak, I. 2008. Seminal plasma proteins of Atlantic halibut (Hippoglossus hippoglossus L.). Fish Physiol. Biochem., 34: 349-355.

Nagahama, Y. 1994. Endocrine regulation of gametogenesis in fish. Int. Dev. Biol., 50: 217-229.

Ohta, H. and Izawa, T. 1996. Diluents for cool storage of the Japanese eel (Anguilla japonica) spermatozoa. Aquaculture, 142: $107-118$

Rana, K. 1995. Preservation of gametes. In: Bromage, N. R. and Roberts, R. J. (Eds.), Broodstock management and egg and larval quality. Cambridge University Press, Cambridge, p. 53-57.

Scott, A. P. and Baynes, S. M. 1980. A review of the biology, handling and storage of salmonid spermatozoa. J. Fish Biol., 17: 707-739.

Shehadeh, Z. H., Kuo, C. M. and Milisen, K. K. 1973. Induced spawning of the grey mullet (Mugil cephalus L.) with 
fractionated salmon pituitary extract. J. Fish Biol., 5: 471-478.

Stoss, J. 1983. Fish gamete preservation and spermatozoa physiology. In: Hoar, W. S., Randal, J. D. and Donaldson, E. M. (Eds.), Fish physiology, New York Academic Press, p. 305-350.

Sukumaran, S., Noble, D., Gopalakrishnan, A. and Sanil, N. K. 2003. Ultrastuctural changes in the spermatozoa of the gold spot mullet Liza parsia (Hamilton-Buchanan) in different diluents during cryopreservation. J. Mar. Biol. Ass. India, 45: 47-53.
Weber, G. M. and Lee, C. S. 1985. Effects of 17a-methyltestosterone on spermatogenesis and spermiation in the grey mullet, Mugil cephalus L. J. Fish Biol., 26: 77-84.

Yeganesh, S., Mojazi Amiri, B. and Alavi, S. M. H. 2007. Motility of Mugil cephalus L. spermatozoa in coelomic fluid, seminal fluid and saline media. J. Appl. Ichthyol., 24: $517-518$.

Zaki, M. I., Garabavi, M. M. E. and Assem, S. S. 1993. Characteristics of spermatogenesis and the production of sperm in the grey mullet, Liza ramada. J. Appl. Ichthyol., 33: $152-158$.

Date of Receipt ～: 22.08 .2016

Date of Acceptance : 10.12 .2016 